\title{
UM NOVO MÉTODO DE CÁLCULO DA POROSIDADE DRENÁVEL
}

\author{
José Elenildo Queiroz ${ }^{1}$
}

RESUMO

Um modo alternativo para cálculo da porosidade drenável a partir de medidas simultâneas de taxas de descarga (q) e altura do lençol freático acima do nível do drenos (h) é apresentado e discutido. A porosidade drenável foi calculada a partir de medidas feitas por Queiroz (1987) e de dados oblidos no campo experimental de drenagem da ESALQ/USP. O procedimento proposto permite que se estime a porosidade drenável com precisão e relativa facilidade, podendo ser aplicado em substituição ao procedimento gráfico utilizado na literatura de drenagem, em condiçōes de regime variável.

Palavras-chave: porosidade drenável, descargas de drenos, drenagem

\section{A NEW METHOD TO COMPUTE DRAINABLE POROSITY}

\begin{abstract}
An alternative way to compute the drainable porosity from measurements of drain discharge rates (q) and height of water table above drain axis (h) is presented and discussed. The drainable porosity was computed from measurements of field obtained by Queiroz (1987) and data obtained at experimental drainage field of the ESALQ/USP. The proposed procedure can be used to estimate the drainable porosity, with accuracy and relative facility, in substitution to the graphic procedure used in the drainage literature, to transient conditions.
\end{abstract}

Key words: drainable porosity, drain discharge rates, drainage

\section{INTRODUÇÃO}

A porosidade drenável $(\mu)$, também denominada macroporosidade ou porosidade efetiva, representa a proporção de macroporos responsáveis pela drenagem e aeração do solo (Kieh1, 1979). Pizarro (1978) e Beltran (1986) definem $\mu$ como uma fração da porosidade total na qual a água se move livremente, cujo valor equivale ao conteúdo de ar presente no solo na capacidade de campo. Para Skaggs el al. (1973) a porosidade drenável é uma fração do volume de solo drenado durante o processo de rebaixamento do lençol freático. Por esta definiçãa, observa-se que o solo não deve, necessariamente, ter atingido a capacidade de campo. Neste caso, o valor de $\mu$ é dado pela razão entre o volume de água drenado livremente e o volume de solo envolvido.

Em condições de regime variável a porosidade drenável é utilizada, juntamente com a condutividade hidráulica do solo saturado (K), para cálculo do espaçamento entre linhas de dreno. Sua determinação em laboratório é obtida pela diferença entre o conteúdo de água na saturação e na capacidade de campo (Pizarro, 1978; Coelho, 1985; Machado, 1988) ou através do ajuste da curva de retenção da água no solo, conforme proposto por Queiroz (1995a). O pouco volume de solo envolvido nesses procedimentos constitui um problema a ser considerado quando da definição de um valor representativo para dimensionamento do sistema de drenagem subterrânea.

A determinação da porosidade drenável em campos experimentais de drenagem ou em modelos reduzidos de laboratório pode ser feila através de mediçōes simultâneas de descarga de drenos (q) e cargas hidráulicas (h). Os resultados obtidos por este procedimento são mais representativos das condições reais estudadas, por envolver um volume maior de solo nas determinações, o que contribui para a redução da variabilidade espacial dos dados; entretanto, a estimativa da $\mu$

1Eng. Agrícola, Dr., Prof. Adjunto., Departamento de Engenharia Florestal/Campus VII/UFPb, CP. 64, 58700-970, Patos, PB, fones: (083)4213397 e 422-1520. Fax: (083)422-2352. 
é leita, comumente, por trabalhosos procedimentos grálicos, mediante a aplicação da teoria de Glover-Dumm, desenvolvida para a condição de regime variável (Dieleman \& Trafford, 1976; Queiroz, 1987; Millar, 1988) o que conduz a estimativas com mais possibilidades de erro que um procedimento matemático e estatístico.

No presente trabalho apresenta-se um modo alternativo de cálculo da porosidade drenável a partir de medidas de taxas de descarga e de cargas hidráulicas, sem necessidade de ulilização de processos grálicos.

\section{MATERIAL E MÉTODOS}

No desenvolvimento da equação para cálculo da porosidade drenável, duas hipóteses básicas foram consideradas:

$\left.1^{a}\right)$ a laxa de descarga varia exponencialmente com o tempo, isto é, $\mathrm{q}(\mathrm{t})=\mathrm{m} . \mathrm{e}^{\mathrm{et}}$, em que $\mathrm{q}(\mathrm{t})$ é a taxa de descarga unitária $\left(\mathrm{L}^{2} \cdot \mathrm{T}^{-1}\right)$, t o tempo (T) e me n os parâmetros empíricos obtidos por regressão linear;

$2^{a}$ ) o rebaixamento do lençol freático no intervalo de tempo considerado ocorre de maneira uniforme e horizontalmente.

$O$ volume de água drenado $\left(V_{d}\right)$ num intervalo de tempo entre dois instantes $\mathrm{t}_{1} \mathrm{e}_{2}$, pode ser expresso como:

$$
\mathrm{V}_{\mathrm{d}}=\ell \int_{\mathrm{t} 1}^{\mathrm{t} 2} \mathrm{q}(\mathrm{t}) \mathrm{dt}
$$

sendo $\ell$ o comprimento ao longo da linha de dreno.

Da primeira hipótese e resolvendo-se a integral da equação (1), deduz-se que:

$$
\mathrm{V}_{\mathrm{d}}=\frac{\ell \mathrm{m}}{\mathrm{n}}\left(\mathrm{e}^{\mathrm{nt}}-1\right)
$$

Como a relação entre o $\mathrm{V}_{\mathrm{d}}$ e o volume de solo $\mathrm{V}$ é a porosidade drenável, resulta que:

$$
\mu=\frac{\ell \mathrm{m}}{V_{n}}\left(e^{\mathrm{nt}}-1\right)
$$

Considerando-se a segunda hipótese, $\mathrm{V}=\mathrm{A} \ell=$ $\mathrm{S} \Delta h \ell$, sendo $\mathrm{A}$ a área seccional de solo drenado, $\Delta h$ é a diferença de carga hidráulica no intervalo de tempo considerado e S o espaçamento entre drenos (experimental, isto é, para determinação da $\mu$ ); assim, substituindo-se $\mathrm{V}$ por $\mathrm{S} \Delta h \ell$ na equação (3) e se expressando $\mu$ em porcentagem, resulta:

$$
\mu(\%)=\frac{100 m}{n S \Delta h}\left(e^{n t}-1\right)
$$

Portanto, determinando-se os coeficientes $m$ e $n$ por análise de regressão e tendo-se os valores de S e de $\Delta h$, oblémse $\mu$. Para aplicação do procedimento proposto foram utilizados dados de campo obtidos por Queiroz (1987) e dados medidos no campo experimental de drenagem do Departamento de Engenharia Rural da ESALQ/USP, conforme a Tabela 1.
Tabela 1. Dados de taxas de descargas e cargas hidráulicas acima do nível dos drenos

\begin{tabular}{cccccc}
\hline & \multicolumn{3}{c}{ Queiroz (1987) } & \multicolumn{3}{c}{ Campo experimental de drenagem da LS $L$ L /USP } \\
\hline $\mathrm{t}_{\mathrm{i}}$ (dias) & $\mathrm{q}_{\mathrm{i}}\left(\mathrm{m}^{\prime} \cdot \mathrm{dia}^{1}\right)$ & $\mathrm{h}_{\mathrm{i}}(\mathrm{m})$ & $\mathrm{t}_{\mathrm{i}}$ (dias) & $\mathrm{q}_{\mathrm{i}}\left(\mathrm{m}^{2} \cdot \mathrm{dia}^{1}\right)$ & $\mathrm{h}_{\mathrm{i}}(\mathrm{m})$ \\
\hline 0,250 & 0,1355 & 0,473 & 0,000 & 0,1079 & 1,000 \\
0,458 & 0,1119 & 0,403 & 0,333 & 0,0951 & - \\
1,000 & 0,0668 & 0,285 & 1,000 & 0,0832 & 0,950 \\
1,500 & 0,0495 & 0,216 & 1,292 & 0,0677 & 0,921 \\
2,042 & 0,0345 & 0,212 & 2,333 & 0,0482 & 0,673 \\
2,500 & 0,0288 & 0,188 & 3,291 & 0,0385 & 0,595 \\
3,083 & 0,0208 & 0,174 & 4,000 & 0,0350 & 0,565 \\
- & - & - & 5,000 & 0,0310 & 0,540 \\
\hline
\end{tabular}

\section{RESULTADOS E DISCUSSÃO}

Da análise de regressão, lipo exponencial, para laxas de descarga em função do tempo, isto é, $\mathrm{q}=\mathrm{q}(\mathrm{t})$, resultou um coeliciente de determinação $\left(\mathrm{r}^{2}\right)$ igual a 0,983 para os dados obtidos por Queiroz (1987) e 0,965 para os dados do campo experimental de drenagem da ESALQ/USP (Figura 1) o que demonstra bom ajuste dos dados, confirmando que a primeira hipótese pode ser assumida.

Os coeficientes empíricos $m$ e $n$ para os dados obtidos por Queiroz (1987) foram 0,14373 e -0,65624, respectivamente. No caso dos dados do campo experimental da ESALQ/USP, esses coeficientes foram $0,10093 \mathrm{e}-0,26250$, respectivamente.
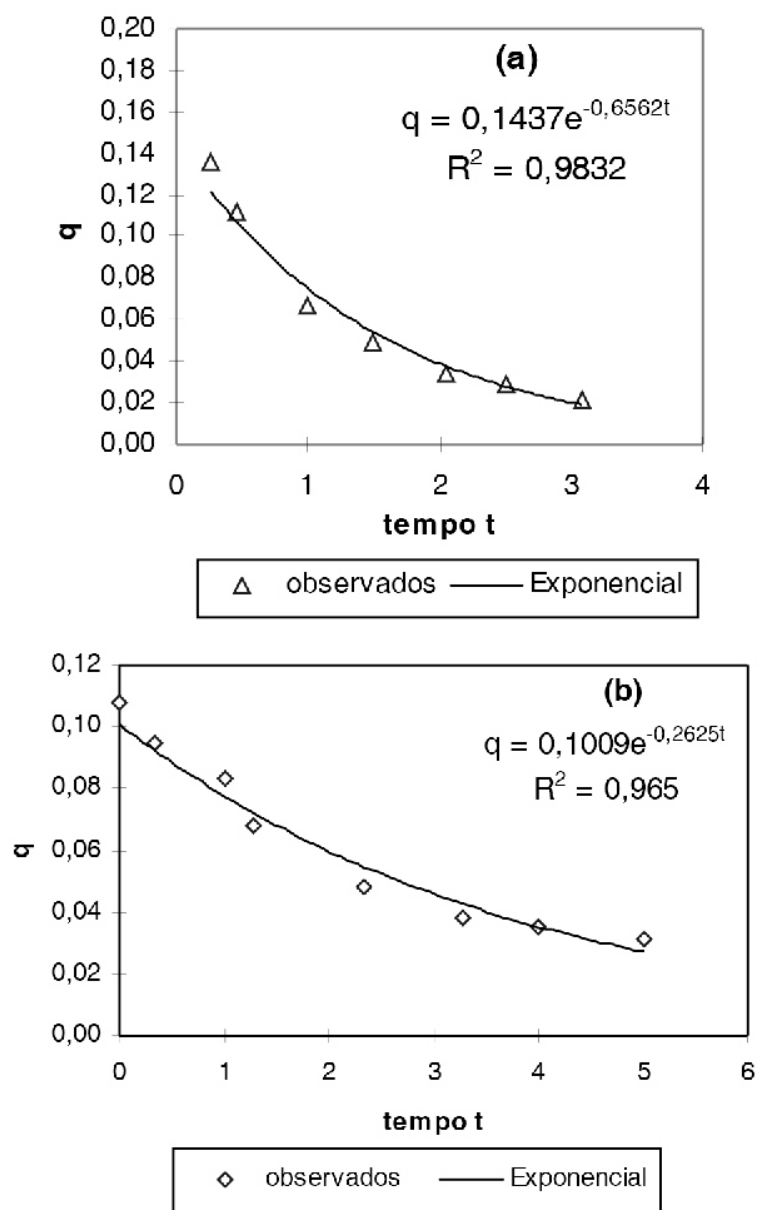

Figura 1. Taxas de descarga $\mathrm{c}\left(\mathrm{m}^{2}\right.$ dia $\left.{ }^{-1}\right)$ em função do tempo (dias) para os dois conjuntos de dados utilizados: (a) dados obtidos por Queiroz (1987) e (b) dados obtidos no campo experimental de drenagem da ESALQ/USP. 
Considerando-se o intervalo de tempo entre as primeira e úllima medidas, as diferenças de carga hidráulica foram: $\Delta h_{1}=$ $0,2987 \mathrm{me} \Delta h_{2}=0,46 \mathrm{~m}$. Com estes valores e os espaçamentos experimentais $\mathrm{S}_{1}=16 \mathrm{~m}$ (sistema-piloto de drenagem instalado no Município de Sumé, Estado da Paraíba) e S, $=10 \mathrm{~m}$ (sistema instalado no campo experimental da ESALQ/USP, Município de Piracicaba, Estado de São Paulo), respectivamente, utilizando-se a equação (4), foram obtidos os seguintes valores de porosidade drenável: $\mu_{1}=3,87 \%$ e $\mu_{2}=6,10 \%$.

Na área-piloto do Município de Sumé, Queiroz (1987) utilizando os procedimentos gráficos sugeridos por Dieleman \& Trafford (1976) obleve porosidade drenável de $5,2 \%$, o que representa $34 \%$ acima do valor de $\mu_{1}$ obtido pelo método aqui proposto. Essa diferença se deve, provavelmente, a erros de aproximações gráficas no método utilizado por Queiroz (1987). No caso dos dados do campo experimental de drenagem da ESALQ/USP, Queiroz (1995b) obteve valor médio igual a $6,413 \%$, a partir de 84 determinações de laboratório o que corresponde a uma diferença de $5 \%$, aproximadamente, acima do valor de $\mu_{2}$. Vale ressaltar que no método de laboratório, o pequeno volume amostral é um fator que contribui para aumentar a variância dos dados, sendo preferível, para fins de drenagem subterrânea, o uso dos métodos de campo, os quais são representativos de um volume maior de solo, o que diminui o efeito da variabilidade espacial.

O método proposto, embora apresente erros de estimativa devido à análise de regressão envolvida, $q=q(t)$, constitui alternativa para o cálculo da porosidade drenável a partir de medidas de q e de h, podendo-se utilizá-lo em substituição ao método grálico convencional, que apresenta maiores possibilidades de erro nas estimativas.

\section{CONCLUSÕES}

O procedimento proposto constitui alternativa para estimativa da porosidade drenável, a partir de medidas de descarga e cargas hidráulicas acima do nível dos drenos, com maior precisão e facilidade de cálculos em relação ao procedimento gráfico utilizado nos manuais de drenagem agrícola, em condições de regime variável.

\section{REFERÊNCIAS BIBLIOGRÁFICAS}

BELTRAN, J.M. Drenaje agrícola. Madrid:Iryda, 1986. v. 1, 239p.

COELHO, E.F. Desempenho de algumas equações de drenagem e dos drenos abertos e cobertos em condições de campo. Viçosa: UFV, 1984. 80 p. (Dissertação de Mestrado).

DIELEMAN, P.J. \& TRAFFORD, B.D. Ensayos de drenaje. Rome: FAO, 1976. 140 p. (Estudios FAO: Riego y Drenaje, $\left.n^{\circ} 28\right)$

KIEHL, E.J. Manual de edafologia. São Paulo: Agronômica Ceres, 1979. 262p.

MACHADO, R.V. Variabilidade espacial de atributos físicohídricos em uma hidrossequência de solos bem a mal drenados. Lavras: ESAL, 1994. 88p. (Dissertação de Mestrado).

MILLAR, A.A. Drenagem de terras agrícolas: bases agronômicas. São Paulo: Editerra, 1988. 306p.

PIZARRO, F. Irenaje agrícola y recuperación de suelos salinos. Madrid: Agrícola Espanhola, 1978. 525p.

QUEIROZ, J.E. Avaliação do desempenho hidráulico de dois sistemas-piloto de drenagem subterrânea usando-se manilhas de barro, no perímetro irrigado de Sumé, PB. Campina Grande: UFPb, 1987. 98p. (Disserlação de mestrado).

QUEIROZ, J.E. Estimativa da porosidade drenável de um solo de várzea em função da tensão da água no solo. Scientia Agrícola, Piracicaba, v.52, n.3, p.469-475, Sel.Dez. 1995a.

QUEIROZ, J.E. Parâmetros hidrodinâmicos de um solo de várzea para fïns de drenagem subterrânea. Piracicaba: ESALQ, 1995b. 167p. (Tese de Doutorado).

SKAGGS, R.W. ; KRIZ, G.J.; BERNAL, R.F. Field evaluation of transient drain spacing equations. Transactions of the

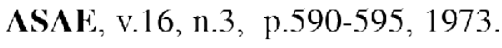

